\title{
Therapeutic Potential of RNA Interference in Pain Medicine
}

\author{
Ping-Heng Tan*, ${ }^{* 1}$ Lin-Cheng Yang ${ }^{1}$, Ru-Rong $\mathrm{Ji}^{2}$
}

\author{
${ }^{I}$ Department of Anesthesiology, E-DA Hospital, I-Shou University, Kaohsiung, Taiwan ${ }^{2}$ Pain Research Center, \\ Department of Anesthesiology, Brigham and Women's Hospital and Harvard Medical School, 75 Francis Street, \\ Medical Research Building, Room 604, Boston, Massachusetts 02115, USA
}

\begin{abstract}
In recent years RNA interference (RNAi) has rapidly become the most widely used tool for gene knockdown due to its high specificity and potency. RNAi is an evolutionarily conserved mechanism for silencing gene expression by targeted degradation of mRNA. In the past decade, hundreds of molecular targets have been identified for their roles in pain modulation. But most molecular targets are not readily druggable with small molecules. RNAi represents a therapeutic approach applicable to these non-druggable targets. There is a rapid increase in the number of studies that use small interfering RNAs (siRNAs) to validate new targets for pain regulation. In this review, we will discuss these painrelated RNAi studies (Table 1). We will also compare the advantages and disadvantages of RNAi with antisense knockdown (Table 2), because antisense oligodeoxynucleotides have been extensively used for target validation in pain research. Although in vivo delivery of siRNA remains to be a challenge, RNAi has a great potential to become a major therapeutic tool for pain management.
\end{abstract}

\section{INTRODUCTION}

Many diseases including chronic pain are associated with uncontrolled gene expression. Therefore, a great research effort has been put on finding compounds that can alter gene expression. One approach was to alter levels of gene expression using antisense technology. Most antisense methods that use single-stranded DNA (ssDNA) or singlestranded RNA (ssRNA) oligonucleotides rely on RNase Hmediated degradation of the target mRNA or blockade of translation for their mechanisms of action [1]. Other pathways have also been exploited with favorable results. For example, 2',5' -oligoadenylate triggers action of RNase L [2]. The first experiment performed in 1978 used antisense oligonucleotides complementary to sequences within their target mRNAs to inhibit gene expression [3]. Since then, different kinds of modified and unmodified DNA and RNA oligonucleotides of typical length of 18-25 nucleotides have been used in antisense studies. In particular, antisense oligodeoxynucleotides (AS-ODN) have been extensively used to validate dozens of molecular targets in pain modulation [4-7]. However, the therapeutic potential of ASODNs is limited due to their low efficacy and selectivity [8] (Table 2).

Twenty years later, Fire, Mello, and collaborators described a process in Caenorhabditis elegans in which long double-stranded RNA (dsRNA) caused suppression of complementary genes and they called this process RNA interference (RNAi) [9]. RNAi exploits a complex, natural pathway that regulates gene expression and includes machinery for sequence-specific mRNA degradation. RNAi was originally discovered as a naturally occurring pathway

\footnotetext{
*Address correspondence to this author at the Department of Anesthesiology, E-DA Hospital, I-Shou University, Kaohsiung, Taiwan; Tel: 886-7-3477902; Fax: 886-7-3423348; E-mail; tanphphd@ @otmail.com
}

in plants and invertebrates $[9,10]$ and was thought to be a nature defense mechanism for viruses or transposons. When long dsRNA are introduced into the cells, they are processed by the endonuclease Dicer into small interfering RNAs (siRNAs) with 21-23 nucleotides. siRNAs are then incorporated into multimember RNA-induced silencing complex (RISC), which unwinds the duplex and uses the antisense strand as a guide to degrade homologous mRNAs [11] (Fig. 1).

In the past years RNAi has become the most widely used technology to suppress gene expression. Specific rules for siRNA design have been developed to produce potent RNAi reagents without the extensive testing needed for the design of traditional antisense ODNs [12,13]. RNAi is much more potent than antisense knockdown. Transfections even with subnanomolar concentrations of RNA sometimes achieve more than $90 \%$ reduction in mRNA levels [14]. In sharp contrast, much high concentrations of antisense-ODNs (70$220 \mathrm{nM}$ ) are required to obtain significant knockdown [15]. Efficacy of RNAi is usually measured as half-maximal inhibition levels or IC50 values. Although efficacy for individual target sites varies widely among siRNAs. It is estimated that the IC50 of siRNAs are 100- to 1000-fold lower than an phosphorothioate AS-ODN directed against the same target [16-18]. Thus RNAi has largely replaced antisense approach for gene knockdown in most in vitro studies and is also showing promise for in vivo applications. The therapeutic application of RNAi has been explored by many pharmaceutical companies.

\section{MECHANISM OF RNA INTERFERENCE}

dsRNAs that cause selective gene silencing make RNAi the gold standard for studying loss of function phenotype. Two types of small RNAs, siRNAs and microRNAs (miRNAs), are known to mediate RNAi. siRNAs are doublestranded RNAs of 21 to 23 nucleotides in length and contain 3 ' overhangs of 2 nucleotides on each strand. siRNAs are 
Table 1. siRNA Application in Pain Research

\begin{tabular}{|c|c|c|c|c|c|c|}
\hline Molecular Target & $\begin{array}{c}\text { Administration } \\
\text { Route }\end{array}$ & Dose & $\begin{array}{c}\text { Transfection } \\
\text { Reagent }\end{array}$ & Pain Condition & Knockdown Efficiency & Reference \\
\hline $\mathrm{P} 2 \mathrm{X} 3$ & Intrathecal injection & $6 \times 400 \mu \mathrm{g}$ & None & Neuropathic pain & $40 \%$ in DRG & Dorn et al. (2004) \\
\hline Delta opioid receptor & Intrathecal injection & $3 \times 2 \mu \mathrm{g}$ & iFect & Opioid analgesia & $38 \%$ in $\mathrm{DRG}, 62 \%$ in $\mathrm{SC}$ & Luo et al. (2005) \\
\hline PGE2 EP4 receptor & Intrathecal injection & $7 \times 200 \mu \mathrm{g}$ & None & Inflammatory pain & $69 \%$ in DRG & Lin et al., (2006) \\
\hline TRPV1 & Intrathecal injection & $1-1000 \mathrm{ng}$ & None & Neuropathic pain & Not examined & $\begin{array}{l}\text { Christoph et al. } \\
\text { (2006) }\end{array}$ \\
\hline TRPV1 & Paratracheal injection & $5 \mu \mathrm{g}$ & Lipofectamine & Inflammatory pain & Not examined & $\begin{array}{l}\text { Kasama et al. } \\
\quad \text { (2007) }\end{array}$ \\
\hline MMP-2 and MMP-9 & Intrathecal injection & $3 \times 2 \mu \mathrm{g}$ & Polyethyleneimine & Neuropathic pain & $50 \%$ in DRG and SC & $\begin{array}{c}\text { Kawasaki et al. } \\
\text { (2008) }\end{array}$ \\
\hline TRPV1 & None & None & $\begin{array}{c}\text { Transgenic shRNA } \\
\text { mice }\end{array}$ & $\begin{array}{l}\text { Inflammatory \& } \\
\text { neuropathic pain }\end{array}$ & $75 \%$ in DRG & $\begin{array}{l}\text { Christoph et al. } \\
\quad \text { (2008) }\end{array}$ \\
\hline Kir 4.1 & $\begin{array}{l}\text { into trigeminal } \\
\text { ganglion }\end{array}$ & $2 \mu \mathrm{g}$ & Lipofectamine & Neuropathic pain & $\begin{array}{l}40 \% \text { in trigeminal } \\
\text { ganglion }\end{array}$ & Vit et al., (2008) \\
\hline Neurotensin receptor-2 & Intrathecal injection & $2 \times 1 \mu \mathrm{g}$ & $\begin{array}{c}\text { Dicer-substrate } \\
\text { siRNA formulated } \\
\text { with iFect }\end{array}$ & Neurotensin analgesia & $\begin{array}{c}52-86 \% \text { in DRG, } 62- \\
70 \% \text { in SC }\end{array}$ & $\begin{array}{l}\text { Louis et al., } \\
\quad(2008)\end{array}$ \\
\hline $\begin{array}{l}\text { Acid-sensing ion } \\
\text { channel (ASIC-3) }\end{array}$ & Intrathecal injection & $3 \times 2 \mu \mathrm{g}$ & iFect & Inflammatory pain & $50-90 \%$ in DRG & $\begin{array}{l}\text { Deval et al., } \\
\quad(2008)\end{array}$ \\
\hline
\end{tabular}

generated from long dsRNAs of exogenous or endogenous origin $[19,20]$ in the cytoplasm by the enzyme Dicer. These siRNAs are processed to single guide (antisense) strands by selective cleavage of the passenger (sense) strand by the enzyme Argonaute $2[21,22]$. The antisense strands are then incorporated into RISC, and RISC is directed by the antisense siRNA strand to homologous target mRNAs that are cleaved by Argonaut 2 in the RISC [23], resulting in reduction of target mRNA levels and subsequent lowering of target protein levels (Fig. 1).

miRNAs are initially transcribed by RNA polymerase II (Pol II) as part of a long primary miRNA (pri-miRNA) precursor $[24,25]$. Mature miRNAs form part of one arm of an 85-nucleotide RNA stem-loop in the pri-miRNA. The first step in miRNA processing is mediated by the RNase III

Table 2. Advantages and Disadvantages of siRNA and AS-ODNs

\begin{tabular}{|c|c|c|}
\hline & siRNA & AS-ODNs \\
\hline \multicolumn{3}{|l|}{ Advantages } \\
\hline Potency & High & Low \\
\hline Selectivity & High & Medium \\
\hline Knockdown duration & Long & Short \\
\hline Target sequence selection & Various sequences & Limited sequences \\
\hline Large-scale target validation & Yes & No \\
\hline Long-term silencing using a vector system & Yes & No \\
\hline Conditional silencing using a vector system & Yes & No \\
\hline \multicolumn{3}{|l|}{ Disadvantages } \\
\hline In vivo delivery & Low efficiency & Low efficiency \\
\hline Toxicity & Possible at high doses & Possible at high doses \\
\hline Off-target effect & Possible at high doses & Not carefully examined \\
\hline
\end{tabular}




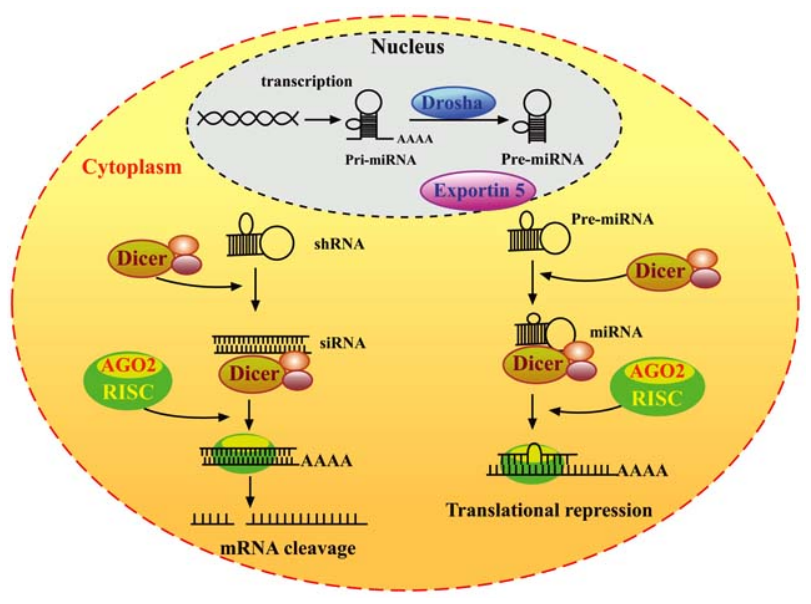

Fig. (1). Pathway of RNA interference. siRNA/miRNA precursors are synthesized in the nucleus. These precursors are first processed there by certain enzyme of the RNAi pathway such as Drosha to form short hairpin structures. The products are then exported into the cytoplasm by small nucleic acid exporter Exportin-5. The short hairpin RNAs are then processed by Dicer in the cytoplasm to produce siRNAs or miRNAs. siRNAs/miRNAs are incorporated into the RNA induced silencing complex, RISC. One strand of the siRNA or miRNA, the guide or antisense strand, is retained in RISC and a homologous target mRNA is bound. Perfectly complementary target binding leads to target degradation; whereas incomplete complementarity leads to inhibition of protein translation from the target.

enzyme Drosha, which cleaves the stem $\sim 22$ nucleotides away from the terminal loop to generate an $\sim 65$-nucleotide pre-miRNA hair-pin intermediate [26]. The pre-miRNA is transported to cytoplasm by the nuclear export factor Exportin-5 [27], where it interacts with enzyme Dicer. Dicer binds the 2-nucleotide 3' overhang found at the base of the pre-miRNA hairpin and cleaves $\sim 22$ nucleotides away from the base, removing the terminal loop and leaving another 2nucleotide 3' overhang. The resultant duplex intermediate of miRNAs are incorporated into RISC and interact Argonaute2 [28]. Once programmed, RISC can down-regulate the expression of homologous mRNAs (Fig. 1).

\section{IN VIVO DELIVERY OF SIRNAS AS A MAJOR CHALLENGE OF RNAI APPROACH}

For in vivo delivery, all classes of gene therapy-related drugs, including siRNAs and antisense ODNs, have the same challenge of achieving distribution in sufficient concentrations at the target tissue. However, all siRNAs need to gain access to the interior of the cell, whereas for other small molecule and protein drugs target cell surface proteins, intracellular access is not required. Effective delivery of nucleic acid-based therapeutic molecules to the central nervous system (CNS) remains a limiting step for RNAi. Although systemic delivery of unmodified Fas siRNA via intravenous injection was shown to specifically reduce Fas mRNA levels and expression of Fas protein in mouse hepatocytes [29], systemic delivery of unmodified siRNAs to the CNS is currently precluded, since siRNAs do not readily cross the brain-blood-barrier (BBB) and are rapidly degraded in vivo by endonucleases and filtered through the renal system. Thus, siRNAs are often mixed with different transfection agents such as lipofectamine, iFect, and polyethyleneimine (PEI) to prevent degradation and increase cellular uptake [30-36]. The use of transfection reagents for delivery enables substantially lower doses and potentially less frequent dosing of siRNA $[31,32,34]$. Recently, a short peptide derived from rabies virus glycoprotein (RVG) enables the transvascular delivery of small interfering RNA (siRNA) to the brain, because this peptide can be taken up by nerve terminals expressing acetylcholine receptors [37]. In particular, intrathecal route is capable of delivering siRNA into spinal cord cells as well as DRG cells [31, 32, 34]. Thus, most siRNA studies for pain research delivered siRNAs with a transfection reagent via intrathecal route (Table $\mathbf{1}$ ).

\section{IN VIVO DELIVERY OF SIRNA FOR PAIN RE- SEARCH}

One of the first studies to apply siRNA strategy to pain research was done by Dorn et al. [30] to target the ATP receptor $\mathrm{P} 2 \mathrm{X} 3$, which was implicated in the induction of neuropathic pain before this study [38]. Dorn and colleagues administered minimally modified siRNAs targeting P2X3 via an intrathecal catheter that is connected to an osmotic pump and examined their effect on neuropathic pain in rats [30]. P2X3 siRNAs were administered by continuous infusion at a dose of $400 \mu \mathrm{g}$ /day for 6 days and produced $\sim 40 \%$ reduction in P2X3 mRNA and protein levels in the dorsal root ganglion (DRG). After the siRNA treatment, rats also exhibited a reduction in neuropathic pain [30]. However, in this study, extremely high doses of siRNAs were used, in the absence of transfection reagent.

In a subsequent study, Tan and coauthors [31] tried a cationic polymer, polyethyleneimine (PEI) to form a 'proton sponge' due to its buffering capacity, which enables PEI to buffer endosomes and induce their rupture to release siRNA into the cytoplasm [39]. Tan et al. synthesized a siRNA to specifically target a subunit of the NMDA receptors, NR2B, as general NMDA receptor antagonists provoke severe side effects [31]. Intrathecal delivery of the RNA-polymer complex was shown to successfully knockdown NR2B expression and formalin-induced spontaneous pain in rats even at a low dose of NR2B siRNA $(5 \mu \mathrm{g})$ [31]. Thus, a bolus intrathecal injection of NR2B siRNA led to a $60 \%$ reduction in NR2B mRNA levels, as assessed by quantitative RT-PCR, and a $80 \%$ reduction in NR2B protein levels, as assessed by Western blot analysis [31] at 7 and 14 days postsiRNA injection. NR2B immunoreactivity was also significantly decreased in the dorsal horn of the spinal cord at 7 days post-siRNA injection. Consistently, the formalin-induced flinching response, an indication of spontaneous pain, was decreased in the second phase.

We also used PEI as a transfection reagent to deliver siRNAs against matrix metalloproteases (MMPs) in a neuropathic pain condition induced by spinal nerve ligation. siRNAs of MMP-9 and MMP-2 were used to validate the role of different MMPs in early- and late-phase of neuropathic pain. Intrathecal injection of 2 x $5 \mu \mathrm{g}$ MMP9 siRNAs in rats effectively suppressed nerve injury-induced MMP-9 upregulation by $>70 \%$ in the DRG and delayed the development of mechanical allodynia, without affecting MMP-2 levels. Nerve ligation-induced allodynia in mice was also 
reversed by intrathecal injection of 2 x $2 \mu \mathrm{g}$ MMP-2 siRNA [34]. To determine whether siRNA is indeed taken up by DRG cells, we intrathecally injected Cy3-labled siRNA mixed with PEI. Three hours later, many DRG neurons showed positive labeling (Fig. 2). Although intense labeling was found near to the edge of DRGs, which is covered by meninges, significant amount of labeling was also observed in neurons deep in the DRG (Fig. 2).

Luo et al. [32] used a cationic lipid delivery agent, iFect and demonstrated that the intrathecal administration of a low dose of siRNA ( $3 \times 2 \mu \mathrm{g})$ against delta opioid receptor ( $\delta \mathrm{OR})$ effectively blocks the analgesia induced by delta opioid receptor in rats. After the treatment, levels of $\delta \mathrm{OR}$ mRNA were reduced by $38 \%$ in the DRG and by $62 \%$ in the lumbar spinal cord. In particular, AlexaFluor546-tagged siRNA fluorescence is clearly detected in both the DRG and spinal cord 24 hours after intrathecal delivery of $2 \mu \mathrm{g}$ of the tagged siRNA mixed with i-Fect ${ }^{\mathrm{TM}}$. In contrast, when fluorescencetagged siRNA is delivered into rats without i-Fect ${ }^{\mathrm{TM}}$, its uptake in the lumbar DRG and spinal cord is very poor [32].

To enable cellular uptake of siRNAs, Guo et al. [40] used a local in vivo electroporation strategy to deliver siRNAs targeting TrkB into the ventromedial medulla (RVM). They demonstrated that the TrkB siRNAs, administrated 4 days before hind paw injection of complete Freund's adjuvant (CFA), completely blocked CFA-induced upregulation of TrkB expression. After the siRNA treatment, animals also exhibited a dose-dependent attenuation of thermal hyperalgesia from $30 \mathrm{~min}$ to $6 \mathrm{~h}$ after CFA inflammation.

For continuous drug infusion, Lin et al. [41] delivered shRNAs targeting EP4 subtype of EP receptor via osmotic minipump, at dose of $200 \mu \mathrm{g} /$ day for 7 days. EP4 receptor is believed to mediate pronociceptive effects of prostaglandin E2. The EP4 shRNAs produced a down-regulation $(70 \%)$ of EP4 mRNA and protein levels in the L5 DRG $(69 \%$ reduction). Knockdown of EP4 receptor also significantly reduced the CFA-induced thermal and mechanical hyper-responsiveness.

Several studies also employed siRNA strategy to investigate the role of capsaicin receptor TRPV1 (transient receptor potential vanilloid type 1). Using the strategy of intrathecal delivery, Christoph and colleagues [42] showed a significant reduction in allodynia in a neuropathic pain model. Viscerally induced pain is also attenuated [43]. Furthermore, Kasama S et al. [33] recently reported that paratracheal administration of TRPV1 siRNA could block TRPV1 upregulation in cervical DRG and abolished inflammatory thermal hyperalgesia induced by CFA. However, thermal hyperalgesia previously established by inflammation was not reversed by injection of siRNA. For comparing different gene silencing strategies, Christoph et al. [42] generated transgenic animals that express a TRPV1directed shRNA. A shRNA sequence directed against the TRPV1 mRNA was inserted in embryonic stem (ES) cells. ShRNA transgenic ES cells were then injected into tetraploid blastocysts. Capsaicin- induced $[\mathrm{Ca} 2+] \mathrm{i}$ changes in small diameter DRG neurons, hypothermia, and nocifensive behaviour measured by duration of licking and biting behavior were all significantly diminished in TRPV1 shRNA transgenic mice. Sensitivity towards noxious heat was reduced. Interestingly, TRPV1 shRNA transgenic mice but not TRPV1 knockout mice show neither mechanical hypersensitivity nor mechanical allodynia after spinal nerve ligation. This discrepancy suggests that developmental compensation often encountered in knockout mice is less significant in shRNA transgenic mice. Thus, transgenic mice expressing shRNA may offer a powerful tool for target validation in pain research.

Another example of using siRNA approach for target validation is to examine the role of Kir4.1, a potassium channel, in pain regulation [35]. Vit et al. show that Kir4.1 is expressed in satellite glial cells of the trigeminal ganglion and this expression was reduced after chronic constriction

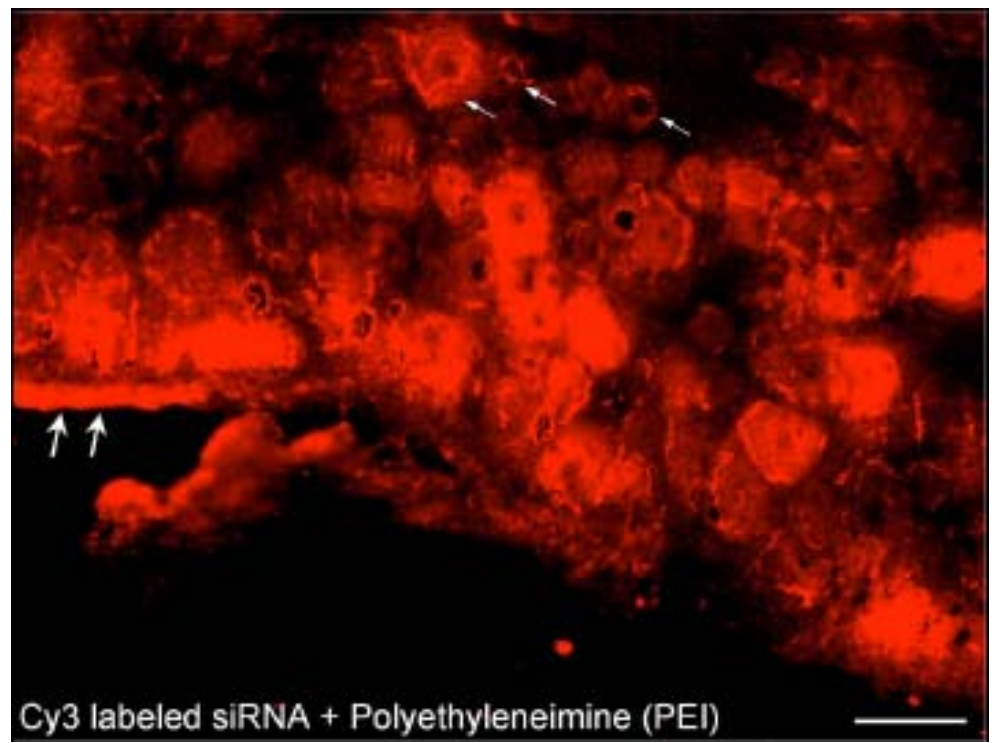

Fig. (2). Up-take of cy3-labeled cyclophylin siRNAs by rat DRG neurons 3 hours after intrathecal injection $(5 \mu \mathrm{g})$. siRNA was mixed with polyethyleneimine (PEI, see reference 34 for details). SiRNA appear to enter DRG via the meninges (large arrows). siRNAs further diffuse deep inside DRG (small arrows). Scale bar, $50 \mu \mathrm{m}$. 
injury of the infraorbital nerve. Specific silencing of Kir4.1 by injecting $15 \mu \mathrm{g}$ siRNA complexing with lipofectamine in the trigeminal ganglion leads to spontaneous and evoked facial pain-like behavior in freely moving rats. The findings correlate a neuropathic pain-like behavior with a change in expression of a single $\mathrm{K}^{+}$channel in peripheral glial cells [35].

Garraway et al. [44] used a recombinant adeno-associated virus (rAAV) vector to express siRNA targeting the NR1 subunit of NMDA receptors. Three weeks after vector injected into the mouse spinal cord dorsal horn, a 60 to $75 \%$ decrease of NR1 mRNA and protein was revealed in the area affected by virus injection. Notably, the spatial knockdown persisted for at least 6 months after a single administration of the vector. The vector-derived siRNA prevented the mechanical allodynia measured at 24 and $48 \mathrm{~h}$ after CFA inflammation. No cellular toxicity measured by nuclear staining and cell integrity was found. The results indicate that vectorderived siRNAs can be used to produce a long-term knockdown of gene expression in the spinal cord.

In $2005 \mathrm{Kim}$ and colleagues [14] demonstrated that 27mer Dicer-substrate siRNA (DsiRNA) is more potent in vitro than standard 21-mer siRNAs. The introduction of a combination of asymmetric 3 '-overhang and DNA bases at the opposing blunt end were shown to induce a more predictable dicing pattern and improve the reliability of this method [45]. This strategy was also successfully demonstrated in pain research [36]. Low dose DsiRNA (0.005 $\mathrm{mg} / \mathrm{kg}$ ), formulated with the cationic lipid i-Fect, was highly efficient in reducing the expression of the neurotensin receptor-2, a G-protein-coupled receptor (GPCR) involved in ascending nociception, in rat spinal cord through intrathecal administration. Along with specific decrease in NTS2 mRNA and protein, there is also a significant loss in the analgesic effect of a selective-NTS2 agonist after administration of DsiRNA, reaching 93\% inhibition for 3-4 days.

\section{POTENTIAL PROBLEMS OF RNAI APPROACH}

In an extreme case, RNAi may cause death of animals. There has been a report demonstrating the death of mice after Pol III promoter-driven expression of shRNAs in the liver [46], in part due to saturation of the transport factor, exportin 5 that ferries miRNAs from the nucleus to the cytoplasm. But the most common problem of RNAi is the off-target problem. While many studies support the potency and specificity of siRNA approaches, the issue of specificity across tissues and cell types remains unresolved. With the use of microarrays, it has become increasingly obvious that introducing foreign siRNAs into the cell alters the expression of non-target genes, as well as target genes [47-49]; as few as six or seven nucleotides complementary to the seed region could result in a specific off-target effect [50] through a miRNA-like mechanism. Off-target effects can be minimized by selecting fewer and more potent siRNAs with minimal matches to off-target genes. Furthermore, chemical modification of the base at position 2 in the guide strand of the siRNA has been shown to greatly reduce off-target effects [51]. Several alogorithms have been used to analyse siRNAs for off-target effects and can be used for more effective siRNA design $[52,53]$.
It has also been shown that some siRNAs and short hairpin RNAs (shRNAs), when introduced into mammalian cells, would activate innate immune responses mediated by protein kinase response (PKR), interferon (IFN), and Tolllike receptors resulting in global gene silencing or inflammatory responses [48, 54-56]. Thus, it is very important to identify the most potent sequences and to ensure that the sequence is specific to the target gene by performing a Blast search and by monitoring genome-wide expression profiles with microarray screens [57]. It is also important not to use high doses of siRNAs. We think for intrathecal injection, a dose of $>10 \mu \mathrm{g}$ siRNA (mixed a transfection regent) may produce off-target effects in rats (Tan and Ji, unpublished observation).

\section{CONCLUSIONS AND FUTURE DIRECTIONS}

Only a few years after discovery of RNAi, siRNA and miRNA have become invaluable tool for research in the field of functional genomics and target validation and in studying loss of function phenotype, including loss of pain phenotypes. Accumulating evidence reviewed above strongly suggests that RNAi is a feasible strategy for the validation of potential pain targets and the development of new pain therapeutics, although in vivo delivery and off-target effects remain to be real challenges.

Although direct delivery of synthetic siRNA with a transfection reagent is easy to carry out, the application of controlled expression vectors is an important development. Regulated RNAi expression has been achieved via ecdysoneor tetracycline-inducible systems $[58,59]$. Tet-based systems have been successfully incorporated into viral vectors allowing stable, inducible silencing in vitro and in vivo [60, 61]. Inducible knockdown in transgenic animals allows researchers to examine the function of genes essential during development in differentiated tissues. Conditional knockdown is also useful for modeling human pathologies in vivo, to induce and revert at will the shutoff of a diseaseinfluencing gene. Moreover, controlled expression can be combined with tissue-specific strategies to allow both temporal and spatial restriction of RNAi. In pain research, this leaves the possibility to restore the exact expression of an endogenous gene once the RNAi vector is silenced or removed and to turn the expression of a gene on-and-off at will. This will provide a possible novel method for short- or long-term management of pain in the future.

Chronic pain is a major public health problem, and there is an unmet demand for new therapeutics. However, many well-validated molecular targets are not modified by drugs. siRNA has the potential to become the next major class of therapeutic drugs, because of its potency and selectivity equally to all molecular targets. This exciting new technology will shortly be within the reach of clinicians, and the number of possible applications, including the treatment of acute and chronic pain syndromes, is rapidly growing. Some clinical trials using RNAi to treat human diseases have begun, and biotechnology companies that focus on RNAibased therapeutics are already publicly traded [62]. We expect to see an RNAi-based trial for the treatment of chronic pain in a near future. 


\section{ACKNOWLEDGEMENT}

This work was supported in parts by National Science Council Grant of Taiwan NSC 97-2314-B-214 -006 -MY3.

\section{REFERENCES}

[1] Crooke ST. Molecular mechanisms of action of antisense drugs. Biochim Biophys Acta 1999; 1489: 31-44.

[2] Adah SA, Bayly SF, Cramer H, Silverman RH, Torrence PF. Chemistry and biochemistry of 2, 5'-oligoadenylate-based antisense strategy. Curr Med Chem 2001; 8: 1189-212.

[3] Zamecnik PC, Stephenson ML. Inhibition of Rous sarcoma virus replication and cell transformation by a specific oligodeoxynucleotide. Proc Natl AcadSci USA 1978; 75: 280-4.

[4] Lucas JJ, Mellström B, Colado MI, Naranjo JR. Molecular mechanisms of pain: serotonin1A receptor agonists trigger transactivation by $\mathrm{c}-\mathrm{fos}$ of the prodynorphin gene in spinal cord neurons. Neuron 1993; 10: 599-611.

[5] Standifer KM, Chien CC, Wahlestedt C, Brown GP, Pasternak GW. Selective loss of delta opioid analgesia and binding by antisense oligodeoxynucleotides to a delta opioid receptor. Neuron 1994; 12: 805-10.

[6] Ji RR, Zhang Q, Bedecs $\mathrm{K}$, et al. Galanin antisense oligonucleotides reduce galanin levels in dorsal root ganglia and induce autotomy in rats after axotomy. Proc Natl Acad Sci USA 1994; 91: 12540-3.

[7] Tsuda M, Shigemoto-Mogami Y, Koizumi S, et al. P2X4 receptors induced in spinal microglia gate tactile allodynia after nerve injury. Nature 2003; 424: 778-83.

[8] Kretschmer-Kazemi FR, Sczakiel G. The activity of siRNA in mammalian cells is related to structural target accessibility: a comparison with antisense oligonucleotides. Nucleic Acids Res 2003; 31: 4417-24.

[9] Fire A, Xu S, Montgomery MK, Kostas SA, Driver SE, Mello CC. Potent and specific genetic interference by double-stranded RNA in caenorhabditis elegans. Nature 1998; 391: $806-11$.

[10] Napoli C, Lemieux C, Jorgensen R. Introduction of a chimeric chalcone synthase gene into petunia results in reversible cosuppression of homologous genes in trans. Plant Cell 1990; 2: 27989.

[11] Hannon GJ, Rossi JJ. Unlocking the potential of the human genome with RNA interference. Nature 2004; 431: 371-8.

[12] Reynolds A, Leake D, Boese Q, Scaringe S, Marshall WS, Khvorova A. Rational siRNA design for RNA interference. Nat Biotechnol 2004; 22: 326-30.

[13] Ui-Tei K, Naito Y, Takahashi F, et al. Guidelines for the selection of highly effective siRNA sequences for mammalian and chick RNA interference. Nucleic Acids Res 2004; 32: 936-48.

[14] Kim DH, Behlke MA, Rose SD, Chang MS, Choi S, Rossi JJ. Synthetic dsRNA Dicer substrates enhance RNAi potency and efficacy. Nat Biotechnol 2005; 23: 222-6.

[15] Grünweller A, Wyszko E, Bieber B, Jahnel R, Erdmann VA, Kurreck J. Comparison of different antisense strategies in mammalian cells using locked nucleic acids, 2'-O-methyl RNA, phosphorothioates and small interfering RNA. Nucleic Acids Res 2003; 31: 3185-93.

[16] Miyagishi M, Hayashi M, Taira K. Comparison of the suppressive effects of antisense oligonucleotides and siRNAs directed against the same targets in mammalian cells. Antisense Nucleic Acid Drug Dev 2003; 13: 1-7.

[17] Drude I, Dombos V, Vauléon S, Müller S, Drugs made of RNA: development and application of engineered RNAs for gene therapy. Mini Res Med Chem 2007; 7: 912-31.

[18] Bertrand JR, Pottier M, Vekris A, Opolon P, Maksimenko A, Malvy C. Comparison of antisense oligonucleotides and siRNAs in cell culture in vivo. Biochem Biophys Res Commun 2002; 296: 1000-4.

[19] Elbashir S, Harborth J, Lendeckel W, Yalcin A, Weber K, Tuschl T. Duplexes of 21-nucleotide RNAs mediate RNA interference in cultured mammalian cells. Nature 2001; 411: 494-8.

[20] Bernstein E, Caudy AA, Hammond SM, Hannon GJ. Role for a bidentate ribonuclease in the initiation step of RNA interference. Nature 2001; 409: 363-6.

[21] Matranga C, Tomari Y, Shin C, Bartel DP, Zamore PD. Passengerstrand cleavage facilitates assembly of siRNA into Ago2containing RNAi enzyme complexes. Cell 2005; 123: 607-20.
[22] Rand TA, Petersen S, Du F, Wang X. Argonaute2 cleaves the antiguide strand of siRNA during RISC activation. Cell 2005; 123 (4): 621-9.

[23] Hammond SM, Boettcher S, Caudy AA, Kobayashi R, Hannon GJ. Argonaute2, a link between genetic and biochemical analyses of RNAi. Science 2001; 293(5532): 1146-50.

[24] Lee Y, Jeon K, Lee JT, Kim S, Kim VN. MicroRNA maturation: stepwise processing and subcellular localization. EMBO J 2002; 21: 4663-70.

[25] Cullen BR. Transcription and processing of human microRNA precursors. Mol Cell 2004; 16: 861-5.

[26] Lee Y, Ahn C, Han J, et al. The nuclear RNase III Drosha initiates microRNA processing. Nature 2003; 425(6956): 415-9.

[27] Yi R, Qin Y, Macara IG, Cullen BR. Exportin-5 mediates the nuclear export of pre-microRNAs and short hairpin RNAs. Genes Dev 2003; 17: 3011-6.

[28] Bartel DP. MicroRNAs: genomics, biogenesis, mechanism, and function. Cell 2004; 116: 281-97.

[29] Song E, Lee SK, Wang J, et al. RNA interference targeting Fas protects mice from fulminant hepatitis. Nat Med 2003; 9: 347-51.

[30] Dorn G, Patel S, Wotherspoon G, et al. siRNA relieves chronic neuropathic pain. Nucleic Acids Res 2004; 32: e49.

[31] Tan PH, Yang LC, Shih HC, Lan KC, Cheng JT. Gene knockdown with intrathecal siRNA of NMDA receptor NR2B subunit reduces formalin-induced nociception in the rat. Gene Ther 2005; 12: 5966.

[32] Luo MC, Zhang DQ, Ma SW, et al. An efficient intrathecal delivery of small interfering RNA to the spinal cord and peripheral neurons. Mol Pain 2005; 1: 29.

[33] Kasama S, Kawakubo M, Suzuki T, Nishizawa T, Ishida A, Nakayama J. RNA interference-mediated knock-down of transient receptor potential vanilloid 1 prevents forepaw inflammatory hyperalgesia in rat. Eur J Neurosci 2007; 25: 2956-63.

[34] Kawasaki Y, Xu ZZ, Wang XY, et al. Distinct roles of matrix metalloproteases in the early- and late-phase development of neuropathic pain. Nat Med 2008; 14: 331-6.

[35] Vit J-P, Ohara PT, Bhargava A, Kelley K, Jasmin L. Silencing the Kir4.1 potassium channel subunit in satellite glial cells of the rat trigeminal ganglion results in pain-like behavior in the absence of nerve injury. J Neurosci 2008; 28: 4161-71.

[36] Dore-Savard L, Roussy G, Dansereau MA, et al. Central Delivery of Dicer-substrate siRNA: a direct application for pain research. Mol Ther 2008; 16: 1331-9.

[37] Kumar P, Wu H, McBride JL, et al. Transvascular delivery of small interfering RNA to the central nervous system. Nature 2007; 448(7149): 39-43.

[38] Barclay J, Patel S, Dorn G, et al. Functional downregulation of $\mathrm{P} 2 \mathrm{X} 3$ receptor subunit in rat sensory neurons reveals a significant role in chronic neuropathic and inflammatory pain. J Neurosci 2002; 22: 8139-47.

[39] Godbey WT, Wu KK, Mikos AG. Tracking the intracellular path of poly (ethylenimine) /DNA complexes for gene delivery. Proc Natl Acad Sci USA 1999; 96: 5177-81.

[40] Guo W, Robbins MT, Wei F, Zou S, Dubner R, Ren K. Supraspinal brain-derived neurotrophic factor signaling: a novel mechanism for descending pain facilitation. J Neurosci 2006; 26: 126-37.

[41] Lin CR, Amaya F, Barrett L, et al. Prostaglandin E2 receptor EP4 contributes to inflammatory pain hypersensitivity. J Pharmacol Exp Ther 2006; 319: 1096-103.

[42] Christoph T, Bahrenberg G, Vry JD, et al. Investigation of TRPV1 loss-of-function phenotypes in transgenic shRNA expressing and knockout mice. Mol Cell Neurosci 2008; 37: 579-89.

[43] Christoph T, Grünwellet A, Mika J. Silencing of vanilloid receptor TRPVl by RNAi reduces neuropathic and visceral pain in vivo. Biochem Biophys Res Commun 2006; 350: 238-43.

[44] Garraway SM, Xu Q, Inturrisi CE. Design and evaluation of small interfering RNAs that target expression of the $N$-Methyl-Daspartate receptor NR1 subunit gene in the spinal cord dorsal horn. J Pharmacol Exp Ther 2007; 322: 982-8.

[45] Rose SD, Kim DH, Amarzguioui M, et al. Functional polarity is introduced by Dicer processing of short substrate RNAs. Nucleic Acids Res 33: 4140-56.

[46] Grimm D, Streetz KL, Jopling CL, et al. Fatality in mice due to oversaturation of cellular microRNA/short hairpin RNA pathways. Nature 2006; 441: 537-41. 
[47] Jackson AL, Bartz SR, Schelter J, et al. Specificity of short interfering RNA determined through gene expression signatures. Proc Natl Acad Sci USA 2003; 100: 6347-52.

[48] Sledz CA, Holko M, de Veer MJ, Silverman RH, Williams BR. Activation of the interferon system by short-interfering RNAs. Nat Cell Biol 2003; 5: 834-9.

[49] Scacheri PC, Rozenblatt-Rosen O, Caplen NJ, et al. Short interfering RNAs can induce unexpected and divergent changes in the levels of untargeted proteins in mammalian cells. Proc Natl Acad Sci USA 2004; 101: 1892-7.

[50] Birmingham A, Anderson EM, Reynolds A, et al. 3' UTR seed matches, but not overall identity, are associated with RNAi offtargets. Nat Methods 2006; 3: 199-204.

[51] Jackson AL, Burchard J, Leake D, et al. Position-specific chemical modification of siRNAs reduces "off-target"transcript silencing. RNA 2006; 12: 1197-205.

[52] Naito Y, Yamada T, Ui-Tei K, Morishita S, Saigo K. si-Direct: highly effective, target-specific siRNA design software for mammalian RNA interference. Nucleic Acids Res 2004; 32: W1249.

[53] Yamada T, Morishita S. Accelerated off-target search algorithm for siRNA. Bioinformatics 2005; 21: 1316-24.

[54] Manche L, Green SR, Schmedt C, Mathews MB. Interactions between double-stranded RNA regulators and the protein kinase DAI. Mol Cell Biol 1992; 12: 5238-48.
[55] Bridge AJ, Pebernard S, Ducraux A, Nicoulaz AL, Iggo R. Induction of an interferon response by RNAi vectors in mammalian cells. Nat Genet 2003; 34, 263-4.

[56] Pebernard S, Iggo RD. Determinants of interferon-stimulated gene induction by RNAi vectors. Differentiation 2004; 72: 103-11.

[57] Clarke PA, te Poele R, Workman P. Gene expression microarray technologies in the development of new therapeutic agents. Eur J Cancer 2004; 40: 2560-91.

[58] Gupta S, Schoer RA, Egan JE, Hannon GJ, Mittal V. Inducible, reversible, and stable RNA interference in mammalian cells. Proc Natl Acad Sci USA 2004; 101: 1927-32.

[59] Matsukura S, Jones PA, Takai D. Establishment of conditional vectors for hairpin siRNA knockdowns. Nucleic Acids Res 2003; 31: e77.

[60] Shin KJ, Wall EA, Zavzavadjian JR, et al. A single lentiviral vector platform for microRNA-based conditional RNA interference and coordinated transgene expression. Proc Natl Acad Sci USA 2006; 103: $13759-64$.

[61] Wiznerowicz M, Trono D. Conditional suppression of cellular genes: lentivirus vector-mediated drug-inducible RNA interference. J Virol 2003; 77: 8957-61.

[62] Castanotto D, Rossi JJ. The promises and pitfalls of RNAinterference-based therapeutics. Nature 2009; 457: 426-33.

Received: April 11, 2009

Revised: April 25, 2009

Accepted: June 17, 2009

(C) Tan et al.; Licensee Bentham Open.

This is an open access article licensed under the terms of the Creative Commons Attribution Non-Commercial License (http://creativecommons.org/licenses/by-nc/3.0/) which permits unrestricted, non-commercial use, distribution and reproduction in any medium, provided the work is properly cited. 